Bangladesh Journal of Bioethics 2015 Vol.6 (1):1-5

\title{
Ethical Relation between Physicians and Pharmaceutical Industries in the Perspectives of Bangladesh
}

\author{
Shahinul Alam ${ }^{1}$, Nahiduzzaman $^{2}$, Monsur Hallaj $^{3}$, Jahangir UI Alam $^{4}$, Shoaib Momen Majumder ${ }^{5}$
}

1. Dr. Md. Shahinul Alam, Associate Professor of Hepatology, Bangabandhu Sheikh Mujib Medical University, Dhaka, Bangladesh. Email: shahinul67@yahoo.com,

2. Resident, Department of Rheumatology, Bangabandhu Sheikh Mujib Medical University, Dhaka, Bangladesh.

3. Assistant Professor, Department of Surgery and Urology. Northern International Medical College, Bangladesh.

4. Resident, Department of Rheumatology, Bangabandhu Sheikh Mujib Medical University, Dhaka, Bangladesh.

5. Resident, Department of Rheumatology, Bangabandhu Sheikh Mujib Medical University, Dhaka, Bangladesh.

\begin{abstract}
Relation between physicians and pharmaceutical industry is required for the benefit of the patient. But it may turn into business and overthrow the patients' benefit. The relation might be in question at present and in future. Several questions are flowing in Bangladesh. To solve these queries we have explored the situation in developed and developing countries. The physicians and associations of pharmaceutical industries developed several ethical guidelines in those countries. They have addressed the long lasting issues on gift provided to physician, cash back, sample, industry sponsored scientific meetings, research and hospitality. There are huge restrictions to ensure the right of the patient's e.g. limitation of inexpensive gift by the pharmaceuticals, avoiding expensive medicine instead of equally effective low priced medicine. We are lacking behind to protect the patient right properly: regulation, adherence to existing guide line, lack of guidance from statutory bodies. The current scenario is far behind the right of patient. In Bangladesh it is not yet addressed either by professionals or by pharmaceutical associations. It is the immediate need to construct a guide line for physicians and pharmaceutical industry of Bangladesh.
\end{abstract}

Key words: Ethics; Physician; Pharmaceutical industry; Gifts; Hospitality; Sponsorship

Introduction: Our patients have to bear the expenses of medicine and other costs of treatment. Very small amount is served by public fund. Two third of expenditure is bored by out of pocket. The drug and its price are regulated by Drug Administration authority under the Ministry of Health and Family Welfare. Clinical trial is at infantile stage. Apprehension over conflicts of interest in medicine is rooted in a concern that professional judgments about the welfare of patients may be inappropriately influenced by a secondary interest — in this case; the personal gain derived from relationships with pharmaceutical companies ${ }^{1}$. A drug company's primary interest is to maximize sales of its product. Physicians do not (or should not) share this goal, but they are the chief conduit for sales. Consequently, physicians have been the central target of marketing strategies ${ }^{2}$. The pharmaceutical industry and professional organizations should anticipate some elements of the gathering storm. Their voluntary initiatives in this heretofore largely unregulated area could be interpreted as an attempt to forestall sterner measures by addressing the kinds of activities. 
The promotion of medicines is very influential and needs to be carefully controlled. The pharmaceutical industry differs from other industries in that its products directly affect the health of patients. The sale of these medicines is strictly controlled through market authorization (registration), prescribing and dispensing regulations. Ethical promotion of medicines is important in order to ensure that medicines are prescribed and used in a rational way. Promotional activities that do not comply with ethical criteria for medicinal pharmaceutical promotion are an important factor contributing to inappropriate overuse and unnecessary costs ${ }^{3}$.

In the world, the rise of the pharmaceutical industry's importance as a funder of mainstream research and education is increasing. Approximately 60 percent of biomedical research and development today is funded by industries ${ }^{4,5}$. Pharmaceutical companies' share of funding for clinical trials is more than 70 percent ${ }^{6,7}$. The industry also shoulders more than half of the costs of continuing medical education ${ }^{8,9}$. Financial entanglement has bred close ties between the industry and physicians. There is hardly a physician practicing today who has not been the beneficiary of small "educational" gifts such as pens and memo pads or lunch for the office staff ${ }^{10}$. Many physicians attend dinners to hear a hired expert talk about a product, take educational trips to resorts, or receive funds in the form of research grants, trainee support, or lucrative consulting fees ${ }^{11,12}$. These benefits are defended as a way to provide useful information for physicians as they address difficult problems in treating their patients. But at what point does the influence become corrosive to the good of the patient ${ }^{13}$ ?

Methods: For the purpose of this review we have gone through the web site of World Health Organization, American Medical Association, World Medical Association, General Medical Council, Bangladesh Medical and Dental Council, Indian Medical Council, Irish Medical Council. Necessity to follow these organizations was as because these organizations have already established the guidelines for their country and for the world as a whole. Exclusive summary was written with the followings: Ethical Criteria for Medicinal Drug Promotion, World Health Organization, Geneva 1988, Self-Regulation of Drug Promotion A Cross-sectional Analysis of Pharmaceutical Marketing Codes and the WHO Ethical Criteria for Medicinal Drug Promotion 2007, Code of Practice for the Pharmaceutical Industry, the Association of the British Pharmaceutical Industry; $2^{\text {nd }}$ edition 2012, OPPI Code for Pharmaceutical Practices, Organization of Pharmaceutical Producer of India; 2012, Guide to Professional Conduct and Ethics for Registered Medical Practitioners. Relationships between Doctors and Industry: Frequently Asked Questions, Irish Medical Council October 2012, Code of Interaction with Health Care Professionals of the Pharmaceutical Research and Manufacturers of America (PhRMA) 2012 and Code of Practice 2012 of the R\&D-based Pharmaceutical Association Committee (RDPAC) of China.

\section{Current status in Bangladesh:}

The Pharmaceutical industries and their business are progressively increasing in the country. Country is earning foreign currencies by exporting drugs. There are huge assumption and speculation about the relationship between physician and pharmaceutical industries in the country. Several stories has been published and broadcasted in the print and electronic medias ${ }^{14}$. Though the existing Bangladesh Medical \& Dental Council Act ${ }^{15}$ prohibit any unethical relation between physician and pharmaceutical industry; there are evidences that pharmaceutical industries are providing cash, hospitality, pleasure trips, medical equipments, books, sponsorship for conferences, workshop, decoration for chamber, professional and non professional gifts for doctors. Clinical trials are very few in the country and pharmaceuticals are not much interested to support this. Clinical trials are regulated by Institutional Review Board/ Bangladesh Medical Research Council. At this stage profession is losing its image and respect, though a very 
small number of physicians are involve with these misconduct. If it is not addressed by professionals it could be dealt by state prosecution as like USA where a third party, a body of federal law dealing with "fraud and abuse" 16 has evolved to the point where it was being used by prosecutors to punish pharmaceutical companies and physicians. In 2002, three leading professional organizations - the American Medical Association ${ }^{17}$, the American College of Physicians, $^{18}$ the Accreditation Council for Continuing Medical Education ${ }^{19}$ —and Pharmaceutical Association ${ }^{20}$ published guidelines regarding physicians' interactions with drug companies. Several other guide lines have been published in last 10 years from Europe and Asia on the abovementioned subject except from Bangladesh. It is the time demand to build up a standard guide line on "Ethical relation between Physician and pharmaceutical industries" for Bangladesh from professionals and from pharmaceuticals.

\section{Leading issues to be addresses in the country}

a. Cash/kickback/ commission: According to the World Medical Association ${ }^{21}$. "The Code provides that payment by or to a physician solely for the referral of a patient is unethical as is the acceptance by a physician of payment of any kind, and in any form, from any source such as a pharmaceutical company or pharmacist". Indian Medical Council Act strictly prohibit this ${ }^{22}$. In USA it is considered as criminal activity and prosecuted by fraud and abuse law ${ }^{23}$.

b. Gifts provided by pharmaceutical company: Gifts are frequently supplied by medical representatives or at events to health-care professionals. Ethical criteria for medicinal drug promotion (WHO-ECPM) mentioned "Gifts offered to members of the medical and allied professions should be secondary to the purpose of the meeting and should be kept to a modest level" 24 . The code analysis demonstrates that some gifts are permitted under strict circumstances. The benefit for the profession or the opportunity for education of the health-care professional plays a key role in the permission of gifts. Apart from the permission of the supply of medical utilities or small gifts for the benefit of the health profession by the various codes, some offers with regard to hospitality are permitted. In the various national codes, requirements should be included to ensure that nothing be offered that would interfere with the independence of the health-care professional's prescribing or dispensing practices. The Association of the British Pharmaceutical Industry (ABPI) permits the supply of promotional aids to health professionals as long as these are inexpensive and relevant to the practice of the recipient's work. The ABPI also mentions a maximum cost of a utility, being six pounds ${ }^{25}$. Utilities for use by patients are also permitted. The ABPI requires that non professional gifts or other material or financial benefits should not be offered to healthcare professionals or administrative staff in order to induce them to prescribe, supply, administer, recommend, buy or sell any medicine ${ }^{26}$.

c. Sample of Drug: According to Organization of Pharmaceutical Producer of India (OPPI) free samples of a pharmaceutical product may be supplied to healthcare professionals or to persons duly authorised by them who are qualified to prescribe such products in order to enhance patient care. Drug samples should not be resold or otherwise misused. ${ }^{26}$ Irish Medical Council further clarifies that the number of such samples of each product that may be supplied to any one recipient in any one year shall be limited; the supply of any such sample is made only in response to a written request, signed and dated, by the recipient; each such sample is marked "free medical sample - not for sale" or words to the like effect ${ }^{27}$.

d.Sponsoring and hospitality of scientific meetings, conferences, seminars and symposium: American Medical Association recommended conference subsidies should meet the following conditions: They should be accepted by conference sponsor, not physician attendees. They do not cover travel, lodging, time, or other personal 
expense of physician attendees who are not faculty. Hospitality subsidies should be limited to modest meals or social events held as part of meeting .Faculty honoraria and reimbursement must be reasonable. Organizers should retain responsibility for and control over selection of content, faculty, educational methods, and materials. Scholarships and special funds for trainees to attend "carefully selected education conferences" are permitted if selection of recipients is controlled by training institution. "Legitimate" conferences or meetings are defined as having the following characteristics: They are primarily dedicated (in time and effort) to objective scientific and educational activities. They are convened to further knowledge on topic presented. They ensure appropriate disclosure of financial support or conflict of interest. Payments for consulting services must be limited to reasonable compensation and reimbursement for travel, lodging, and meal expenses; must be "genuine" services, not "token". Physicians may accept gifts at the conference from pharmaceutical companies under the following conditions: The gift must be primarily for the benefit of patients and be primarily related to the physician's work. The gift must be of insubstantial value and must not be cash. Drug samples permitted for physicians; personal and family use of the samples also permitted, provided that it does not interfere with patient access to the samples. ${ }^{13}$ These criteria are also supported in UK and Ireland ${ }^{25,27 .}$

Implementation: Further background research is required for present situation and on feasibility and usefulness of a guideline. Motivational work, awareness through training, conference and workshop by Bangladesh Medical Association and other professional organization will break the ground of darkness. Directorate of Health Services and Drug Administration may collaborate with pharmaceutical industry and physician to construct a guide line for the nation and further implementation of it.

Conclusion: The relationship between physician and pharmaceutical industry requires excellent ethical value. It might be in question at present and in future. In developed countries and our neighbor country had establish and

published their status. A practice guideline is essential for Bangladesh regarding this issue. Professional organization and pharmaceutical association could take the initiative to reflect the transparency of relationship.

Acknowledgement: We thankfully acknowledge the contribution of Center for Medical Ethics Education and Research (CMER) for inspiring us to write this article

\section{References:}

6. Thompson DF. Understanding financial conflicts of interest. N Engl J Med 1993; 329:573-6.

7. Rosenthal MB, Berndt ER, Donohue JM, Frank RG, Epstein AM. Promotion of prescription drugs to consumers. N Engl J Med 2002; 346:498-505.

8. WHO. Rational use of medicines: progress in implementing the WHO medicines strategy. WHO Executive Board 2006; 118th Session 11 Provisional agenda item 5.3 EB118/6.

9. Bekelman JE, Li Y, Gross CP. Scope and impact of financial conflicts of interest in biomedical research: a systematic review. JAMA 2003; 289:454-65.

10. DiMasi JA, Hansen RW, Grabowski HG. The price of innovation: new estimates of drug development costs. J Health Econ 2003; 22:151-85.

11. Bodenheimer T. Uneasy alliance: clinical investigators and the pharmaceutical industry. N Engl J Med 2000; 342:1539-44.

12. Morin K, Rakatansky H, Riddick FA Jr, et al. Managing conflicts of interest in the conduct of clinical trials. JAMA 2002; 287:78-84. 
13. Greider K. The big fix: how the pharmaceutical industry rips off American consumers. New York: Public Affairs, 2003.

14. Relman AS. Defending professional independence: ACCME's proposed new guidelines for commercial support of CME. JAMA 2003; 289:2418-20.

15. Wazana A. Physicians and the pharmaceutical industry: is a gift ever just a gift? JAMA 2000; 283:373-80.

16. Moses H III, Braunwald E, Martin JB, Thier SO. Collaborating with industry - choices for the academic medical center. N Engl J Med 2002; 347:1371-5.

17. Chren MM, Landefeld CS. Physicians' behavior and their interactions with drug companies: a controlled study of physicians who requested additions to a hospital drug formulary. JAMA 1994; 271: 684-9.

18. David M, Michel M, Troyen A. Financial Conflicts of Interest in Physicians' Relationships with the Pharmaceutical Industry - Self-Regulation in the Shadow of Federal Prosecution. N Engl J Med 2004; 351, 1891 - 1900.

19. https://video.search.yahoo.com/video/play; ylt=A2Klo9YWS79UcAQAQW77w8QF; ylu=X3oDMTBycTlydWI1BH NIYwNzcgRzbGsDdmlkBHZOaWQDBGdwb3MDOA--?p=jamuna+television+prescription+360+degree

20. Medical and Dental Council Act. XVI of 1980 and approved by the Council in its meeting held on 24.3.1983

21. Havighurst CC, Blumstein JF, Brennan TA. Health care law and policy: readings, notes, and questions. 2 nd ed. New York: Foundation Press, 1998.

22. American Medical Association. Opinion of the Council on Ethical and Judicial Affairs, E-8.061. (Accessed October 7, 2004, at http://www.ama- ssn.org/ama/pub/category/4001.html.)

23. Coyle SL. Physician-industry relations. 1. Individual physicians. Ann Intern Med 2002; 136:396-402.

24. Accreditation Council for Continuing Medical Education. Standards for commercial support of continuing medical education. http://www.accme.org/incoming/17 system98 essential_areas.pdf.)

25. Pharmaceutical Research and Manufacturers of America. Code on interactions with healthcare professionals. http://www.phrma.org/publications/policy/2004-01-19.

26. http://www.wma.net/e/meetings/leaders1.htm

27. The Indian Medical Council (Professional conduct, Etiquette and Ethics) Regulations, 2002.

28. Department of Health and Human Services, Office of Inspector General. OIG compliance program guidance for pharmaceutical manufacturers. Fed Regist 2003; 68(86):23731-43.

29. Ethical criteria for medicinal drug promotion. World Health Organization, Geneva 1988.

30. Code of practice for the pharmaceutical industry. The Association of the British Pharmaceutical Industry; $2^{\text {nd }}$ edition 2012

31. OPPI code for pharmaceutical practices. Organization of Pharmaceutical Producer of India; 2012.

32. Guide to professional conduct and ethics for registered medical practitioners. Relationships between doctors and industry: Frequently Asked Questions. Irish Medical Council October 2012.

Conflict of interest: There is no conflict of interest between the authors and no financial relation with any person or organization regarding this review. 